\title{
LA INDEPENDENCIA DE CUBA DESDE LA MIRADA DE LA METRÓPOLI: EL SEPARATISTA (1895) DE EDUARDO LÓPEZ BAGO
}

\author{
Victoria Galván González
}

\begin{abstract}
RESUMEN
El tratamiento de la independencia de Cuba en la novela española del siglo XIX es el asunto que abordamos en este trabajo. Se escribieron muy pocas novelas sobre ello, salvo, entre otras, $E l$ Separatista (1895) de Eduardo López Bago. El relato recrea las diferencias entre los intereses de la metrópoli y los de la colonia, con la evocación de las varias posiciones que allí se debatieron. El punto de vista que se impone al final es el del autor, defensor de la no separación de Cuba de la metrópoli. Palabras clave: Eduardo López Bago, novela, El Separatista, independencia de Cuba.
\end{abstract}

\begin{abstract}
The treatment of the independence of Cuba in the Spanish novel of nighteenth century is the subject that we approached in this work. Few novels were written very on it, safe, among others, the Separatist (1895) of Eduardo López Bago. The story recreates the differences between the interests of the metropolis and those of the colony, with the evocation of the several positions that struggled there. The point of view that prevails in the end is the one of the author, defender of the non separation of Cuba of the metropolis.

Key words: Eduardo López Bago, novel, El Separatista, independence of Cuba.
\end{abstract}

Las relaciones entre Cuba y España en el período previo a la independencia de la isla en 1898 han sido objeto de polémicos debates, tanto desde la perspectiva cubana como desde la española, desde el nacionalismo cubano y desde las posiciones reformistas, autonomistas, anexionistas e independentistas. En este contexto complejo para la metrópoli, habida cuenta de las conocidas consecuencias para la economía y la política (Álvarez 2001: 567- 607; Elorza y Hernández 1998: 452- 462; Jover 1991), la pérdida colonial no dejó testimonios relevantes

Dra. Victoria Galván González. Profesora Titular de Literatura Española de la Universidad de Las Palmas, Gran Canaria.

Correo electrónico: vgalvan@dfe.ulpgc.es

Recepción: 12- 2- 2009

Aceptación: 6- 3- 2009 
en las grandes novelas españolas del XIX. Al respecto, Antonio Prieto (1997: 236), en un estudio sobre esta presencia-ausencia entre los grandes novelistas, apunta algunos nombres poco conocidos del panorama literario español coetáneo. En la nómina que recaba aparecen los nombres de Aurelio Pérez Zamora, Sor Milagros o secretos de Cuba (1897); José Nogales Nogales, El último patriota (1901); Francisco de Ulacia, El caudillo, novela cubana (1910) o Ciges Aparicio, Impresiones de la Cabaña (1910). No menciona, sin embargo, el testimonio sugerente que aporta Eduardo López Bago con su novela El Separatista, publicada en Cuba en mayo de 1895, escrita al poco de llegar el autor a la isla en el mes de marzo. Por otra parte, la narrativa cubana que aborda los efectos del colonialismo cuenta con una bibliografía ${ }^{1}$ notable, en especial en relación con el esclavismo y los problemas raciales (Arias 1995; Barreda 1978; Benítez Rojo 1988: 169- 186; Casanova-Marengo 2002; Chang-Rodríguez y de Beer 1989; Kutzinski 1993; Luis 1981; Netchinsky 1986; Rivas 1990).

Eduardo López Bago (1853-1931), nacido en Alicante y fiel exponente del naturalismo radical en España, había partido para América en 1890. Durante siete años permanece en el continente americano en lo que fue una emigración voluntaria. Antes de llegar a Cuba viaja a Buenos Aires, donde publica la novela Carne importada, un drama sobre la inmigración con duras críticas a la metrópoli. Continúa su periplo por México y Puerto Rico. En la isla de Cuba conoce de cerca los acontecimientos que conducen a la independencia en 1898. En su trabajo como periodista colabora activamente con la escritora Eva Canel ${ }^{2}$ por el mantenimiento de la colonia, postura que sostiene en sus escritos y que constituye el núcleo ideológico de la novela que comentamos aquí.

López Bago (Fernández 1995) fue un escritor comprometido con su presente, que pretende llevar hasta sus últimas consecuencias los postulados naturalistas de Émile Zola (Fernández 1995: 90- 98), de quien se proclama acérrimo defensor. Pretende afianzar en la novela española de los años ochenta del XIX sus postulados estéticos, por considerar que es la única vía para regenerar, a su juicio, el lamentable estado de las letras y de la novela en España. Se aparta del idealismo y del espiritualismo contemporáneos practicados por autores como Valera, Pereda o Pérez Galdós, para escribir novelas a partir del programa científico-médico que Claude Bernard predica en sus obras.

Su proyecto literario quiere transformar la sociedad y las corrupciones de toda laya por la vía de la novela comprometida, que baja a pie de calle, a las barricadas, término que emplea en una de sus novelas, El Cura, alejándose de los salones y de las cursis reuniones de sociedad y de la que denomina, con cierto desprecio, la "novela bonita" (1996: 232). Al respecto, y para reforzar sus planteamientos ético-literarios, muchas de sus novelas van precedidas de apéndices explicativos que muestran y enfatizan los mensajes elaborados literariamente en ellas y las posiciones ideológicas que los articulan. Son un documento imprescindible para medir los matices ideológicos de su pensamiento, orientado a la crítica radical de la política de la Restauración, aunque no exento de ambigüedades.

Con estos presupuestos ideó escribir una tetralogía sobre la realidad contemporánea de Cuba en el siglo XIX y su historia previa a la independencia (El Bandolero, La Gente de Color y Gobernador General), pero sólo escribe la que comentamos en estas páginas. En el apéndice a El Separatista ya advierte que el resultado de su viaje por el continente americano no puede ser más desagradable y triste. Quiere hacer, en cuanto le sea posible, una reproducción exacta, completa, sincera del medio social y de la época, porque esta preocupación es la que justifican la razón, las necesidades de la inteligencia y el interés del público (López Bago 1997: 312). 
Pretensiones que, como puede imaginarse, no se cumplen al pie de la letra. El objetivo de escribir con escalpelo presenta no pocas fisuras en el relato sobre la Cuba contemporánea, las inherentes a la ilusión realista-naturalista. Sus palabras son éstas:

Batalla no doy ninguna. No ataco ni defiendo. Exposición de hechos, observación y experimento, aplicados a cosas y personas, con la inexorable indiferencia de opinión que debe ser inspiración única del arte que anhela fortalecerse en la ciencia y mirar la Naturaleza y la Humanidad cara a cara...(1997: 83).

El contenido de la novela se resume en la biografía del protagonista, Lico Godínez, relatada en catorce capítulos. Es un joven criollo, furibundo defensor del separatismo e hijo de uno de los combatientes de la Guerra Grande, hijo del grito de Yara. En síntesis, se representa la evolución-conversión del personaje separatista hacia una postura panhispana y autonomista, que solo fía sus esperanzas en el segundo regreso a la isla del general Martínez Campos en 1895. En la primera parte de la obra, se narra la autodestrucción moral y física del personaje en clave de novela naturalista con una detallada información sobre el separatismo en la Cuba contemporánea. La vida del personaje da un giro al enamorarse de Solita Valiente, española, profesora de piano de su hermana Charita y viuda de un militar español. Se entrecruzan en el relato la historia de amor con las diferencias de perspectiva política que ambos sostienen. Lico representa el separatismo de algunos jóvenes criollos y Solita el discurso de un metropolitano que observa con la objetividad e imparcialidad que, a juicio del narrador, merecen los espectadores ajenos.

Podría decirse que Lico es la metáfora de la Cuba criolla y Solita de la España moderna que sueñan López Bago y otros contemporáneos españoles, críticos con la política colonial, pero enemigos de la independencia. La historia de amor funciona a modo de gozne para dar entrada en la segunda parte de la novela a la evolución de Lico, que abandona las posiciones separatistas para asumir el discurso de Solita, que representa la voz del español "razonable", frente a los desalmados que han llegado a la isla, tal y como se declara en las instancias narrativas de la novela. En sus palabras se recogen todos los discursos de críticas al gobierno y a la administración colonial, a la desidia, a la inestabilidad y a la dureza del gobierno español, pero que, en último término, quieren salvaguardar y fortalecer la imagen de una nación española posible sin la eminente pérdida de las últimas colonias americanas, de la que también da cuenta la obra.

Todo ello queda reforzado en la novela con la intervención de una voz a la que se reviste de autoridad y que detenta el poder científico, el doctor Pérez, que atiende a Lico enfermo, tras batirse en duelo con un amigo. El recurso de López Bago a la voz de la ciencia y de la medicina es habitual en sus obras, acorde con los principios del naturalismo radical, apreciable en novelistas coetáneos, como puede leerse en Alejandro Sawa o José Zahonero. Se trata de un artificio por el cual el novelista refuerza su confianza en el método científico como único medio válido para solventar los problemas sociales que afectan a la nación y a las sociedades urbanas del presente decimonónico, materia recurrente de sus novelas.

Así que, al amparo de las declaraciones en favor de la imparcialidad, en la narración la balanza se inclina de forma palmaria del lado de estos personajes, héroes del progreso en materia científica o, como diría Foucault (2004: 374), se desplaza el discurso tradicional y el lenguaje se desliza del lado de la objetividad, apoyada en la episteme moderna.

El diagnóstico que de Cuba efectúa el doctor Pérez, junto a la dualidad que integra con Solita Valiente, contrasta con las apreciaciones de Lico y otros personajes en la primera mitad del relato. Cierto es que la novela incluye un panorama relativamente completo de la realidad 
social y política de Cuba a partir del carnaval de 1895, cuando se produce el primer intento independentista (levantamiento de Matanzas y Oriente), que culmina con los sucesos de 1898. Este contempla la perspectiva de los revolucionarios de la Guerra Grande en el personaje del padre de Lico y de sus amigos, la de los anexionistas en Pepe Martín, amigo de Lico, la del criollismo puro en la sala de armas de Lafourcade, etc. Falta, por otra parte, la perspectiva de la población negra. A este respecto, López Bago se hace eco del racismo propio del criollismo y de los peninsulares. Lico y su padre temen la rebelión negra.

Si analizamos en detalle las posiciones políticas y sociales literaturizadas en la novela de López Bago, se constatan los siguientes hitos:

$1^{\circ}$ - Se recrea el ambiente prebélico que vive la isla, en un retrato de los miedos de la sociedad criolla, en las conversaciones secretas de los compañeros de armas de Lico con Lafourcade, mezcla de criollo y francés, y convencido de las reformas que prometía el gobierno de España.

$2^{\circ}$ - Alusión a los primeros momentos del movimiento de independencia en la época de Tacón con el pronunciamiento del general Manuel Lorenzo en Santiago de Cuba. Se corresponde en la novela con el bisabuelo de Lico Godínez (1997: 34- 35).

$3^{\circ}$ - El padre de Lico, guerrillero de Yara, que firmó la paz de Zanjón, hace catorce años. Es uno de los 37 hombres de Céspedes del ingenio de Demajagua. Cuando Lico regresa de su viaje por Europa, con su estancia en Madrid, que genera algunas dudas sobre su separatismo, su padre lo recibe con la frase: "Muera España. Viva Cuba libre". Su objetivo, y el de su hijo hasta su conversión, es vengar a los vencidos de Zanjón, seguir la causa del separatismo de Cuba.

$4^{\circ}$ - La postura de Lico Godínez, que representa a la juventud criolla habanera, que cree en el separatismo, pero con diferencias y con algunas dudas con respecto a la generación del padre. El narrador patentiza en todo momento la distancia cronológica que media entre ambos. Las siguientes palabras revelan el pensamiento del personaje-narrador:

\footnotetext{
Después de su viaje por Europa, durante los días de la navegación, antojábasele más aherrojada ahora, más sometida después de la paz aquella, estipulada, según José Godínez, según su padre, como se estipulan las cláusulas para un negocio mercantil. Aherrojada a sus culpas propias más que a las peninsulares, a su falta de fe, que ya se había visto comprobada durante la lucha, a su falta de fe y a su falta de un verdadero caudillo. Ahora, ahora, pasados los años, veíase bien claro que para combatir en Cuba hubieran sido precisos ideales más positivos que acompañaran al ideal de independencia. Caracteres menos románticos y un dictador mejor que aquella Cámara, que unas veces se ensañó con Quesada, otras con Céspedes, y otras se humilló ante el motín y la indisciplina, hasta caer rendida por sus propias vacilaciones y debilidades... (1997: 115- 116).
}

Esta valoración de la Guerra Grande coincide con el análisis que buena parte de los historiadores sostiene en el presente (Moreno Fraginals 1995; Navarro García 1991).

$5^{\circ}$ - Críticas a la metrópoli. No se minimizan, por otra parte, las críticas al comportamiento de los gobiernos de la Restauración, como suele llevar a cabo el autor en otras obras suyas. En otro momento de la novela se afirma que la alternancia de partidos en el poder, la sucesión de Antonio Cánovas del Castillo y Práxedes Mateo Sagasta dejará en la historia una impronta negativa. Asimismo, se aprecia una actitud escéptica ante los proyectos de Maura, ministro de Ultramar en 1892, cuando el gobierno de Sagasta, convencido de la necesidad de introducir reformas en las colonias, pero con notables ambivalencias. Como afirma Emilio de Diego García: “CCómo armonizar las ventajas de un mercado restringido por los intereses de la metrópoli y favorecer simultáneamente a los exportadores y comerciantes cubanos en una coyuntura económica tan dispar para ambos bandos?” (1996: 103). Todo quedará en un 
segundo término ante figuras como la de Martínez Campos, engrandecida por el narrador y por los personajes, presentado en la novela como auténtico y único héroe, al que se apela en los últimos capítulos como una solución válida para los males de Cuba.

En la parte de la novela que pivota en torno al separatismo se exponen en detalle las debilidades y los fallos de las actuaciones de la metrópoli. Aunque, finalmente, triunfe en la novela un punto de vista colonial, prima una dura crítica de las actuaciones de la metrópoli, la que sostenían los intelectuales críticos españoles con el gobierno. En este sentido, la propuesta de López Bago coincide con aquellos que en España eran partidarios de una política colonial antimonárquica. El autor parece próximo a las posturas de los republicanos, que quieren un colonialismo ilustrado, libre de abusos y de corruptelas. Los republicanos evolucionaron desde una visión asimilacionista hacia una autonomista, que aceptaba un estatuto particular para las colonias, pero sin pensar en una independencia.

Por tanto, el punto de vista que domina en la obra es contrario a la política colonial practicada por los gobiernos españoles durante la Restauración. La ideología del régimen, como ha estudiado Carlos Serrano (1996: 73- 87), se sustenta en una política peninsular, con los intereses puestos en el Régimen y en la Corona, que dependían de los intereses oligárquicos. Se patentizaron estas posiciones en los duros ataques lanzados contra el pacificador de Zanjón por parte de los extremistas, pero transmutado, por otra parte, en un héroe para el narrador de la novela y para el propio López Bago, que declara:

\begin{abstract}
Allá dejó en Madrid la lucha eterna y mezquina de los hombres políticos. Él venía buscando la corporal y el estruendo de las armas que tienen más grandeza. "Por nuestras ideas", decían allá los motes y los emblemas en que unos proclamaban la doctrina conservadora, otros la liberal y ninguno de los paladines tenía para defenderlas otros entusiasmos que los de la fe en su ambición, en la suerte, en las picardigüelas del jefe y en la paciencia del jefe y en la paciencia del pueblo, ;paciencia de los que se desengañan y de los que se cansan! "Por la Patria y por el Rey" era lo que llevaba escrito en su bandera, en mote tan claro y, enarbolándola tan alto que aun los mismos que patria sin rey querían tuvieron que admirar siempre la ruda franqueza con que aquel campeón se alzaba la visera y la fuerza con que vibraba su entusiasta grito de guerra dominando todos los ruidos de la batalla (1997: 284).
\end{abstract}

$6^{\circ}$ - Críticas a la administración de la colonia por parte de los criollos.

$7^{\circ}$ - Mención de otras posiciones políticas: autonomistas, reformistas y unionistas.

$8^{\circ}$ - Ninguna mención del Partido Revolucionario que funda poco antes de estas fechas Martí, ni alusiones a sus propuestas políticas. El silencio de su nombre ha de entenderse desde el rechazo frontal de López Bago a la autodeterminación de los pueblos.

Resulta de gran interés en este relato, por tanto, la construcción y la imagen de la nación española en oposición a la idea de una nación cubana, ambas en liza, desde los primeros signos del nacionalismo cubano a finales del siglo XVIII, hasta el preciso momento cronológico en que se escribe la novela, 1895. Fecha en la que los historiadores acuerdan que tanto en América como en España se asumía como inevitable la escisión de Cuba de la metrópoli y en la que comienza el 98. López Bago vierte diferentes discursos a lo largo de la novela que pretenden reproducir las varias posiciones políticas imperantes, pero el manejo del punto de vista eleva a la categoría de discurso dominante la necesidad de mantener a Cuba unida a la nación española. Esta postura se impone sobre las otras desde criterios racionales, a juicio del autor, tal y como declara en el apéndice a la novela. La instancia de la razón aquí proyectada es la que, en aras de una pretendida objetividad aséptica, entroniza, en la perspectiva de los defensores de la independencia, las fragilidades del universo político y epistemológico de la metrópoli. No obstante, se opone a la idea de la existencia de una nación cubana, a la posibilidad de construirla o a cualquier medida para la obtención de la independencia política. 
Si analizamos los hechos representados desde la óptica de los excluidos en la obra, es decir, la de los colonizados, los intentos de legitimar los juicios que emanan de la voz autorial, detentador de las posiciones de la metrópoli, desvela todas las debilidades y las ambigüedades surgidas en el proceso histórico narrado en la novela. Es evidente que la perspectiva nacionalista de López Bago no coincide con la de los que quieren una Cuba libre, en lo que puede calificarse de "deseo bifurcado", en palabras de A. Benítez Rojo.

A medida que avanza la novela, el punto de vista autorial, amplificado en el apéndice, minimiza la fuerza de las otras voces discordantes. Todo ello a pesar de las palabras del doctor Pérez cuando comenta las posibles soluciones al problema cubano. Las recetas del doctor contemplarían el éxito del separatismo, como correspondería a la estricta aplicación de la metodología científica en la construcción de la trama de la obra, como pretende el narrador, y acorde a lo declarado por el autor en los paratextos. Para este objeto de potenciar una perspectiva sobre otras se sirve de argumentos y recursos concretos, como el empleo de técnicas y procedimientos próximos al folletín.

En la necesaria reconstrucción del ambiente prebélico que vive la isla en esas fechas, en lo que Martí denominaba una etapa de "reposo turbulento", desde las primeras páginas se evidencia un detalle relevante en el ideal de nación que se imagina: la nostalgia recurrente del heroísmo vivido en la Guerra Grande, interpretado por Godínez y por el narrador con el código literario del Romanticismo. Este aspecto nos parece crucial por el contraste que se mantiene en el texto con la inminente guerra del 95 . El padre de Lico y sus amigos representan los ideales heroicos de la insurrección que llevaron al Pacto de Zanjón, con las promesas de reformas que se tornaron insuficientes para sus reivindicaciones de libertad y que son presentadas en la obra con el malestar de las clases criollas contemporáneas. Toda alusión en el texto a la guerra precedente, frente a la inmediata del 95, es presentada en clave de exaltación de los valores de los guerreros de Yara, vistos desde el presente de la generación de Lico con cierta condescendencia y con dudas acerca de la vigencia de su legado en el presente histórico.

En el capítulo V se produce un enfrentamiento entre padre e hijo, tras asistir ambos a la tertulia que los viejos guerrilleros frecuentaban. El padre cree en una Cuba libre, pero no ve la realidad del mismo modo que en la antigua guerra. Su escepticismo cede paso al reconocimiento de la evidencia de los intereses económicos que mueven a los separatistas, que ven en la independencia un negocio, pues esta ha sido el gran negocio en Cuba. El hijo, por el contrario, sostiene posturas más idealistas. Cree en la pureza de los pretéritos ideales heroicos y no comparte el espectáculo descorazonador del presente. Lico no quiere, además, entre los insurrectos ni a bandoleros, ni a negros. Sus palabras son éstas:

\footnotetext{
¡Valiente república nueva debida no a los esfuerzos de sus hijos, fundada no por un grupo de héroes, sino por asesinos, secuestradores, cuatreros, incendiarios, ladrones y negros! En las cosas puras debe estar siempre la pureza... (1997: 164).
}

Este discurso es desmentido por el padre, que ve en la independencia un negocio en el que participan de consuno españoles aliados con los insurrectos; estos transmutados ahora en delincuentes de todo signo. No deja de constituir una ficción, o una suerte de romance clásico, que mitifica a unos guerreros puros, los de Yara, en oposición a los devaluados protagonistas del presente. Se percibe en la novela la tensión entre el ideal, el sueño de una unión armónica de Cuba y España, y el diagnóstico de la realidad histórica. Se pueden aplicar aquí las palabras de Fernando Aínsa, en su estudio sobre Eugenio María de Hostos: 
la obra de Eugenio María de Hostos, como la mayoría de los autores del período, refleja el conflicto no dirimido entre el diagnóstico de la realidad que se pretende riguroso científicamente y la visión de un futuro proyectado como idealidad, notas agudizadas del romanticismo-positivista en que su generación traduce la tensión entre el ser de la realidad y el deber ser de la utopía (1991: 313).

Con la salvedad de que ambos escritores proyectan un análisis de la realidad cubana en direcciones harto distantes.

Se expresan en el texto de López Bago, por otra parte, los temores de la metrópoli a la igualdad racial, utilizados por la misma como argumento de oposición al separatismo. La idealización de los valores de pureza, ligados a la pasada guerra, a juicio del personaje y del narrador, sirve de apoyo a la idea de una nación cubana excluyente, que no contará con la participación de los negros, sostenedores del sistema económico de la colonia, como se sabe. Más adelante, en el proceso evolutivo del personaje, el rechazo del separatismo y la defensa de la autonomía y de las reformas para Cuba se explican por la negación del anexionismo y por la amenaza de la rebelión negra.

El concepto de nación que subyace aquí deriva de una visión europeísta que imagina una nación moderna paneuropea, en este caso España, dependiente de un centro regulador que está en Europa y que tiene en Cuba una prolongación y derivación naturales desde siempre, como afirma el personaje de Solita. En la obra se critica a las repúblicas hispanoamericanas, descritas como enemigas de la metrópoli, pero también de los pueblos americanos. La frase que resume esta visión la enuncia el doctor Pérez:

\footnotetext{
Cuba libre, Cuba independiente. ¡Hábrase visto mayor desatino! ¡Una república de Andorra en medio del mar! Una cosa tan ridícula entre los rangos democráticos como lo es en las dinastías reinantes el principado de Mónaco. Le digo a usted que América abusa... ¡Abusa! Y Europa acabará por perder la paciencia (1997: 258- 259).
}

Bien es cierto que en la novela se incorpora el separatismo en las voces del padre de Lico, Lico y Pérez Martín. Pero, como se ha dicho, el punto de vista evoluciona del pluriperspectivismo inicial a la excluyente preeminencia de la autoridad del médico. La dimensión centralista de la metrópoli que se advierte en estas acusaciones choca frontalmente con las denuncias que se leen en los textos de Simón Bolívar o en Martí, entre otras voces. Cuando el primero declara en las Cartas de Jamaica que en el sistema español los americanos no ocupan otro lugar en la sociedad que el papel de siervos propios para el trabajo: "se nos vejaba con una conducta que además de privarnos de los derechos de libertad que nos correspondían, nos dejaban en una especie de infancia permanente con respecto a las transacciones públicas" (1997: 14- 15).

Una voz más cercana, que es evocada en la novela, es la que representan los letrados nacionalistas Antonio Saco, Arango, Parreño, José Luz Caballero o Domingo del Monte. Se alude a sus proyectos de reformas materiales y políticas en la línea antiindependentista, que se asumen al final de la novela en el punto de vista de Lico, del doctor Pérez y del narrador, con sus propuestas de colaboración con un nacionalismo anticolonialista, pero no independentista. De Saco habría que traer a colación estas palabras de su obra, defendidas por López Bago en la novela:

¿Qué necesidad hay de acudir a las armas para obtener lo que se puede alcanzar con sólo la fuerza de la opinión, respetuosa y enérgicamente manifestada? Tomando el camino seguro que nos indica la prudencia y nuestra propia conservación, evitaremos trastornos y guerras civiles; mantendremos y fortificaremos de día en día nuestra nacionalidad (1998: 57).

Aunque el discurso de Saco para la construcción de la nación pasa por el trayecto desde Cuba frente a España. El de López Bago se dirige desde España hacia Cuba. 
En el apéndice final, López Bago expone sus recelos ante la guerra y su defensa de las reformas, al margen de los reformistas, unionistas y autonomistas, pero en consonancia con sus discursos de cambios sin separación, como puede apreciarse en las siguientes palabras:

\footnotetext{
Hubo un tiempo en que la guerra tuvo su razón de ser en la Isla de Cuba. Por eso fue, por eso existió. Hoy no tiene razón ni derecho. Cien hombres que quieren valen más que cien mil que tienen fuerza pero no más que los que tienen, con la fuerza de cien mil, toda la razón de su parte.

Una separación. Dejemos sin considerar que siempre es dolorosa. No discutamos lo indiscutible, entendiéndose por tal que de las dos entidades unidas la que más pierde al quedar sola, la que más expuesta está es la más débil, la más pequeña, la que no conoce del valor que tiene quien la sirve de apoyo, compañera y guía, hasta que todo esto se pierde.

¿Separarse de qué? De sí mismo. Esto es imposible.

La idea separatista es un romanticismo que se deja seducir por la sonoridad de unas cuantas palabras que hoy día sólo tienen la peligrosa hermosura de la forma (1997: 298).
}

Son fácilmente reconocibles, por otra parte, en las consideraciones del doctor Pérez contra la idea de la independencia, algunos de los requisitos para la construcción de las naciones, tal y como han explicado Anderson (1993) y Bhabha (2006). El primero apunta a que la creación de una nación se sustenta en el legado dinástico, aparte de la comunidad religiosa y de la aprehensión del tiempo. Esto es, en el concepto de linaje, al que se apela en el texto citado arriba, cuando se habla del rango democrático de las naciones europeas. Estas se apoyan en una lejana herencia que las legitima. En la novela, el doctor Pérez arremete contra las democracias americanas, al censurar los regímenes parlamentarios de Paraguay y Méjico (López Bago 1997: 259). Prosigue apuntando a la juventud de América como causa de la debilidad de las nuevas democracias, que está con "sus nacionalidades como niño con zapatos nuevos" (1997: 260). Concluye afirmando que malos cubanos son los que desean la independencia para Cuba, que terminará siendo una "merienda de negros" y "toda la isla convertida en un palenque" (1997: 260).

Parece desatender aquí el personaje, portavoz del autor, la idea de Tocqueville de que precisamente en América la democracia parecía formar parte del plan divino, tal y como expresa en su Democracia (Hermosa 2003: 9). Aunque Tocqueville se refiere al Norte, parece que en la perspectiva autorial de la novela no interesa esta propuesta, a pesar de que se cite a Benjamin Franklin y su opúsculo sobre cómo provocar la rebelión de las colonias. Estas fragilidades de los gobiernos de América Latina, no obstante, ya fueron objeto de preocupación en los textos de Bolívar en las primeras décadas de la centuria, cuando promovía para el éxito de los gobiernos soberanos americanos aprender de los del Norte:

\footnotetext{
En tanto que nuestros compatriotas no adquieran los talentos y las virtudes de políticas que distinguen a nuestros hermanos del Norte, los sistemas enteramente populares, lejos de sernos favorables, temo mucho que vengan a ser nuestra ruina (Bolívar 2007: 20).
}

Se pone de manifiesto en el texto de la novela, asimismo, la contraposición entre una imagen de la nación europea, fortalecida por sus legítimas y antiguas democracias, en oposición a las débiles democracias americanas, que no cuentan con una tradición que las apoye. Se evidencian en esta postura netamente eurocéntrica los temores del autor a la propagación de las ideas liberales de la Ilustración, que junto con el aumento del control y de las equívocas actuaciones de la monarquía española en el XIX, denunciadas también en la novela, estimulan los movimientos de separación, tal y como Anderson (1993: 95) ha señalado en su estudio sobre el criollismo americano, al explicar los orígenes de las nuevas naciones.

Por esta razón de las diferencias metropolitana y cubana sobre la idoneidad de las democracias se citan en la obra de López Bago las tesis de Gustave Le Bon. El etnólogo, 
médico y arqueólogo francés explica la desnaturalización que se produce en Asia o en América por la aplicación y propagación de las teorías revolucionarias, que sí funcionaron en Europa. Esta tesis conecta con las teorías de la diferencia natural de los pueblos que desarrolla el racismo decimonónico, apoyado en teorías pseudo-científicas en la senda de Buffon y Pauw, que explican desde la ciencia la diferencia y jerarquía entre las razas que deriva en la justificación del esclavismo. Gustave Le Bon, en su obra La Révolution française et la psychologie des révolutions (1983: 50), expresa la importancia de la raza en la génesis de las revoluciones. Las diferencias debidas a las leyes naturales producen efectos harto distantes entre un pueblo y otro. Palabras que López Bago en El Separatista expresa así: “Gustavo Le Bon da como causa de las insurrecciones en que tuvo que luchar Francia en Oriente el error que cometió llevando las reformas más liberales y las ideas más modernas de Europa a los pueblos destinados a la inmovilidad asiática para los cuales era ya demasiado la civilización musulmana" (1997: 289- 290).

En esta misma senda cabe mencionar las tesis de Stuart Mill acerca del progreso y la razón en el gobierno representativo, en su conocida obra Del gobierno representativo (1865). López Bago trae a colación la idea de $\mathrm{Mill}^{3}$ de que el mejor gobierno es el que aspira al progreso y que el orden representa una parte de las cualidades que se piden a un buen gobierno, pero no su esencia. La alteración del orden puede anular un estado de cosas, pero puede significar un progreso. Con todo ello pretende justificar su argumento de que la idea separatista es romántica y que la sublevación va en contra del sentido común.

No puede obviarse otra raíz ideológica presente en la novela como son las teorías de Hegel, en la senda de otros pensadores europeos, que no contemplan para América las mismas apuestas de estado y de nación que para Europa y que solo perciben en el viejo continente la concreción del concepto moderno de estado. En primer término, López Bago se hace eco de la teoría hegeliana de estado moderno esbozada en sus Principios de la filosofía del derecho (1821), con la tesis del estado como síntesis de la oposición entre la familia y la sociedad civil, punto de detención y de reposo del espíritu objetivo, explicado en el apéndice de la novela y concretado en la narración en las palabras de Lico, cuando conversa con Solita. En Hegel, el estado es la forma más elevada de la ética objetiva, la plenitud de la idea moral y la realización de la libertad objetiva. Es el universal concreto, en el que el individuo aislado no tiene sentido en su concepto de realidad y de absoluto concreto que proyecta. La realidad concreta se recupera por medio de la familia, fundamento de la sociedad burguesa, junto al Estado, máxima concreción de la realidad orgánica. Lico sueña con una patria y una familia como elementos que dan sentido al hombre: "El amor a la tierra donde se nace y la mujer que elegimos para que de ella nazcan nuestros hijos en esta tierra" (1997: 199).

Por otra parte, en la idea de estado de Hegel, explicada en su Filosofía de la historia, el espíritu objetivo evolucionó desde los pueblos orientales al modelo germánico. En la medida en que la filosofía latinoamericana ha fundamentado su identidad a partir de la crítica y del rechazo del pensamiento eurocéntrico de Hegel, se ha entendido su pensamiento sobre América como incomprensión y desconocimiento de su realidad. Los argumentos de la falta de esencia de América se aprecian en declaraciones como estas:

La América debe separarse del terreno sobre el cual ha transcurrido hasta ahora la historia universal. Lo que ha sucedido allí hasta ahora es tan sólo el eco del viejo mundo y la expresión de una vida extraña; ahora bien, como país del porvenir, no nos interesa aquí de una manera general; pues en relación con la historia tenemos que ver con lo que ha sido y lo que es, mas, en filosofía, no con lo que ha sido ni deberá ser solamente, sino con lo que es y eternamente será, con la razón, y con ella tenemos bastante trabajo (Hegel 1940: 9). 
En el apéndice de El separatista (1997: 297), López Bago apuesta por la fórmula Abárzuza-Maura para Cuba, a la que califica de hegeliana, al unir la nación sin suprimir el carácter especial de la nacionalidad, concediendo a las localidades la libertad de administrar sus intereses. A su juicio: "En toda América sólo hay unas islas donde se desarrolle con vida normal el estado social y político. Las islas de Cuba y Puerto Rico que no gozan de tristes independencias, sino de todas las alegrías de la libertad" (1997: 297). De la actitud del autor se desprende su intencionada exclusión del nombre y de las tesis de Martí, a cuyos discursos se opone López Bago con claridad con el silencio textual mencionado.

En la novela se impone de forma gradual la aplicación del espíritu racional que debe mirar hacia un modelo político para Cuba, ya esbozado en la filosofía política europea. Se propone para la obra una perspectiva docente-terapéutica, que diseña una imagen del estado y de la nación española muy ligados al pensamiento europeo contemporáneo. Sus recetas están en la dimensión naturalista en la que se ampara López Bago, como hace en el resto de su producción literaria, al escribir novelas a partir de problemas concretos. En el caso de Cuba, para el autor, a través del personaje de Lico y del doctor Pérez o Solita, la solución pasa por la estricta aplicación de las teorías modernas europeas del estado y la constitución de las naciones europeas, desde una actitud crítica con las actuaciones arbitrarias de los gobiernos monárquicos.

Pero todo ello desatendiendo buena parte del pensamiento anticolonial, antiesclavista que defienden los letrados de las colonias, aunque comparta y coincida con ellos en no pocas cuestiones, habida cuenta de su proximidad al pensamiento de Saco y al de otros nacionalistas cubanos, de los autonomistas y reformistas. El autor en su afán por legitimar sus posturas políticas se preocupa de incluir en la narración las tesis y los discursos contemporáneos en boga sobre la nación cubana o española.

En relación con la aprehensión del tiempo, factor indispensable para la forja de una nación en la teoría de Anderson (1993: 43- 62), como decíamos arriba, no se distingue para su creación la historia de la cosmología. En la novela se minimiza la distancia geográfica de Cuba de España y las diferencias de identidad. Para Solita Cuba es España, los kilómetros no cuentan. Para Lico la distancia es crucial para abrir una brecha entre ambos espacios físicos. En relación estrecha con la historia, para Solita los orígenes de España y Cuba se funden en una unidad perdida en el tiempo (afirma que Dios sabe desde cuando los cubanos son españoles). La historia del continente, resumida en la novela con referencia a los hitos más relevantes del XIX para Cuba, queda en segundo término para Solita, que expone con claridad la idea de un pasado común, con unos orígenes difuminados que eliminan la mención de la conquista y que favorece la imagen de una única nación, en la que han de convivir armónicamente España y Cuba. Ella aboga por la idea de una nación española que integre de forma natural lo marginal, lo alejado por razones geográficas, en la totalidad, sin odios, como bien ha explicado Foucault (Bhabha 2006: 86), que sostiene que la antinomia ley/orden posibilita la moderna racionalidad política. Cuba, que se ve marginada y expoliada por la metrópoli, como denuncian Lico y todos los letrados cubanos del XIX, deviene para Solita un único cuerpo nacional, sin fisuras ni ambigüedades.

Acerca del olvido de los agravios e injusticias padecidos por Cuba, que se evocan a lo largo de la novela, se pueden traer a colación las tesis de Bhabha, apoyado en Renan, de cómo la articulación de la nación se sustenta en la voluntad de serlo a partir del olvido y del silencio ${ }^{4}$. El olvido de la historia del pasado, presentes en las palabras de Solita en la línea de Renan, es la base de la narración de una nación: "Mediante esta sintaxis del olvido - o de la obligación de olvidar-se hace visible la identificación problemática de un pueblo nacional" (Bhabha 2006: 98). 
Lo que reclama el personaje es la necesidad de construir la nación sobre las bases del silencio de las diferencias. Aunque la idea de nación que se propone aquí esté en una posición opuesta a la de los letrados nacionalistas de Cuba.

Sobre el racismo aludido más arriba, dice Anderson que la aparición de grupos sociales visibles de euroamericanos, como consecuencia del crecimiento de las comunidades criollas, genera un estilo de pensamiento que anticipa el racismo moderno. También, aunque resulte contradictorio, la expansión de la Ilustración y de la prensa (en la novela el médico le dice a Lico que sus venenos son la prensa y el café) producen una escisión entre metropolitanos y criollos, perceptible a lo largo de la novela. Además Lico, como criollo, asume la perspectiva de los letrados nacionalistas, herederos de los ideales ilustrados y contrarios a la inserción de los negros en el proyecto de la identidad nacional cubana, como en estas palabras: "¡Valiente república nueva debida no a los esfuerzos de sus hijos, fundada no por un grupo de héroes, sino por asesinos, secuestradores, cuatreros, incendiarios, ladrones y negros! En las cosas puras debe estar siempre la pureza, lo respetable merece tratarse con respeto..." (1997: 164).

Irma Llorens (1998: 87) explica que resulta paradójico que el nacionalismo cubano reproduzca las posturas antidemocráticas del colonialismo español, oponiéndose a ellas. Se piensa en una nacionalidad cubana como lugar geográfico, con una tradición, unas costumbres, un carácter, una literatura compartidos, pero se niega a los negros el derecho a formar parte de la nación cubana ${ }^{5}$. Se ampara el personaje de Lico en una pretendida pureza, que representa las estrategias textuales a las que se acude a la hora de narrar la nación, propio de los nacionalismos decimonónicos. Al igual que hacen los letrados nacionalistas cubanos, se evoca aquí una construcción de la identidad colectiva asentada en la sensación de unidad, de aplicación del sentido común y de la trascendencia del proyecto de la nueva nación. Como se sabe, todos los teóricos del concepto de identidad nacional hablan del sentido de comunidad para definirlo, aunque éste se apoye en la fragmentación social (Eagleton 1998: 75). En este sentido, por tanto, la voz autorial de la novela coincide con los letrados de la colonia. De la lectura de la obra, como ha podido comprobarse, se desprenden algunas de las posiciones políticas e ideológicas de la metrópoli respecto a la colonia en los enconados debates que se sucedieron antes de la independencia de Cuba. Al respecto, esta novela de López Bago resulta sugerente en la medida en que apenas se escribieron novelas sobre el asunto desde España, como indicamos al principio de este trabajo.

\section{Notas}

1. No pretendemos reproducir aquí toda la bibliografía que existe sobre este tema, solo algunas referencias.

2. La editora española Eva Canel recorrió varios países del continente americano, primero con su esposo y después sola al enviudar. En los años noventa, desde 1891, se encuentra en Cuba, donde fundó revistas satíricas como La Cotorra. Órgana política-satírica y libérrima. Semanario políticosatírico que no sabe tirar al sable y no se bate más que a picotazos (1891-1893). Participa de la vida política y evolucionó desde el republicanismo hacia la monarquía, el general Weyler y la defensa de su patria (Palmer 2008: 399).

3. Estas ideas se pueden leer en el segundo capítulo de la obra de John Stuart Mill, "Que sea una buena forma de gobierno", Del gobierno representativo (1865). 
4. "Or l'essence d'une nation est que tous les individus aient beaucoup de choses en commun, et aussi que tous aient oublié bien des choses. Aucun citoyen français ne sait s’il est burgonde, alain, taïfale, visigoth; tout citoyen français doit avoir oublié la Saint-Barthélemy, les massacres du Midi au XIII e siècle. Il n'y a pas en France dix familles qui puissent fournir la preuve d'une origine franque, et encore une telle preuve serait-elle essentiellement défectueuse, par suite de mille croisements inconnus qui peuvent déranger tous les systèmes des généalogistes" (Renan 1882: chapitre I).

5. En la novela, en el capítulo V, se alude a la conspiración "de la Escalera” de 1844 y la participación del poeta Plácido. Para el narrador la intención era el exterminio de los blancos para hacerse dueños de la isla. También se menciona, en el capítulo IV, a Cirilo Villaverde, a José de la Luz Caballero y a José María Heredia. Del primero, el personaje de Solita afirma que es un mal español, pero un buen cubano. Es evidente que en el texto se dirimen las dos visiones contrapuestas acerca de las tensiones que afectan a la identidad nacional: de Cuba a España y de España a Cuba.

\section{Bibliografía}

Álvarez Junco, José. 2001. Mater dolorosa. La idea de España en el siglo XIX. Madrid: Taurus, 567-607.

Aínsa, Fernando. 1991. "Hostos y la unidad de América Latina: Raíces histórica de una utopía necesaria". Citado por Fell, Claude (1999), en: Naranjo, Consuelo y Carlos Serrano (eds.). Madrid: Consejo Superior de Investigaciones Científicas, Casa de Velázquez, 313.

Anderson, Benedict. 1993. Comunidades imaginadas. Reflexiones sobre el origen y la difusión del nacionalismo. México: Fondo de Cultura Económica.

Arias, Salvador (ed.). 1995. Esclavitud y narrativa en el siglo XIX cubano: enfoques recientes. La Habana: Editorial Academia.

Bhabha, Homi. 2006. "Diseminación. El tiempo, el relato y los márgenes de la nación moderna". Naciones literarias. Dolores Romero López (ed.). Barcelona: Anthropos Editorial.

Barreda, Pedro. 1979. The Black Protagonist in the Cuban Novel. Page Bancroft (trad.). Amherst: University of Massachussetts Press.

Benítez Rojo, Antonio. 1988. "Ideología y literatura: la novela antiesclavista en Cuba (18351839”. Cuadernos Hispanoamericanos. 451- 452: 169-186.

Bolívar, Simón. 2007. "Cartas de Jamaica”, Obra política y constitucional. Estudio preliminar, antología y notas de Eduardo Rozo Acuña. Madrid: Tecnos, Clásicos del Pensamiento, Tercer milenio, 14-15.

Le Bon, Gustave. 1983. La Révolution française et la Psychologie des Révolutions. Paris: Les Amis de Gustave Le Bon. 
Casanova-Marengo, Ilia. 2002. El intersticio de la colonia. Ruptura y mediación en la narrativa antiesclavista cubana. Madrid: Iberoamericana.

Chang-Rodríguez Raquel y Gabriella de Beer (eds.). 1989. La historia en la literatura iberoamericana. Memorias del XXVI Congreso del Instituto Internacional de Literatura Iberoamericana. New York: Ediciones del Norte.

de Diego García, Emilio. 1996. "Las reformas de Maura, ¿la última oportunidad política en las Antillas?”. En: de Diego, E. (ed..). Madrid: Cursos de Verano de El Escorial, Editorial Complutense, 103.

de Diego García, Emilio (ed.). 1996. 1895: La Guerra en Cuba y la España de la Restauración. Madrid: Cursos de Verano de El Escorial, Editorial Complutense.

Eagleton, Terry. 1998. "Nationalism: Irony and Commitment”. Citado en: Eagleton, T. et al. Nationalism. Colonialism and Literature. En: Llorens, Irma (1998), 75.

Elorza, Antonio y Elena Hernández Sandoica. 1998. La guerra de Cuba (1895-1898). Madrid: Alianza Editorial, 452- 462.

Fell, Claude. 1999. "Representación simbólica de España. Puerto Rico y Cuba en la Peregrinación de Bayoán, de Eugenio María de Hostos". Imágenes e imaginarios nacionales en el Ultramar español. Consuelo Naranjo Orovio y Carlos Serrano (eds.). Madrid: Consejo Superior de Investigaciones Científicas, Casa de Velázquez.

Fernández, Pura. 1995. Eduardo López Bago y el Naturalismo radical. La novela y el mercado literario en el siglo XIX. Amsterdam-Atlanta: Editions Rodopi.

Fernández, Pura y Marie-Linda Ortega (ed. y dir.). 2008. La mujer de letras o la letraherida. Discursos y representaciones sobre la mujer escritora en el siglo XIX. Madrid: Consejo Superior de Investigaciones Científicas.

Foucault, Michel. 1990. Tecnologías del yo. En: Bhabha, H (2006). Barcelona: Paidós.

2004. Las palabras y las cosas. Una arqueología de las ciencias humanas. Madrid: Siglo XXI.

Hegel. 1940. Lecciones de Filosofía de la Historia. Madrid: Revista de Occidente.

Hermosa Andújar, Antonio. 2003. "Pobreza y democracia en Tocqueville”. En: Hermosa, Antonio (ed. y trad.). Madrid: Editorial Trotta, 9.

Hermosa Andujar, Antonio (ed. y trad.) Pobreza y democracia en Tocqueville. (Mèmories sur Le Paupèrisme Lettre sur Le Paupèrisme en Normandie). Madrid: Editorial Trotta. 
Jover Zamora, José Antonio. 1991. La civilización española a mediados del siglo XIX. Madrid: Espasa-Calpe, Austral Historia.

Kutzinski, Vera M. 1993. Sugars' Secrets. Race and the Erotics of Cuban Nationalism. Charlottesville and London: University Press of Virginia.

López Bago, Eduardo. 1996. El Cura. (caso de incesto. Novela médico-social). J.I. Ferreras (ed.). Madrid: Ediciones Vosa.

1997. El separatista. Francisco Gutiérrez Carbajo (ed.). Madrid: Castalia.

Luis, William. 1981. "The Antislavery Novel ant the Concept of Modernity". Cuban Studies /Estudios Cubanos. 2 (1): 33- 47.

Llorens, Irma. 1998. Nacionalismo y literatura. Constitución e institucionalización de la "República de las letras cubanas”. Lleida: Asociación Española de Estudios Literarios Hispanoamericanos, Edicions de la Universitat de Lleida.

Moreno Fraginals, Manuel. 1995. Cuba / España. España / Cuba. Historia común. Barcelona: Editorial Crítica.

Navarro García, Luis. 1991. La independencia de Cuba. Madrid: Editorial Mapfre.

Prieto, Antonio. 1997. “El testimonio de Cuba en la narrativa”. En: Ramos, Demetrio y Emilio de Diego (eds.). Madrid: Editorial Complutense, 236.

Ramos, Demetrio y Emilio de Diego (eds.). 1997. Cuba, Puerto Rico y Filipinas en la perspectiva del 98. Madrid: Editorial Complutense.

Renan, Ernest. 1882. Qu'est-ce qu'une nation? http://ourworld.compuserve.com/homepages/ bib_lisieux/. Collection électronique de la Bibliothèque Municipale de Lisieux.

Rivas, Mercedes. 1990. Literatura y esclavitud en la novela cubana del siglo XIX. Sevilla: Escuela de Estudios Hispano-Americano de Sevilla.

Saco, José Antonio. 1998. Colección de papeles. En: Llorens, Irma. Lleida: Asociación Española de Estudios Literarios Hispanoamericanos, Edicions de la Universitat de Lleida, 57.

Serrano, Carlos. 1996. "Aspectos ideológicos del conflicto cubano". En: de Diego, Emilio García (ed.). Madrid: Cursos de Verano de El Escorial, Editorial Complutense, 73-87.

Simón Palmer, Ma del Carmen. 2008. "Vivir de la literatura. Los inicios de la escritora profesional". En: Fernández, Pura y Marie- Linda Ortega (eds). Madrid: Consejo Superior de Investigaciones Científicas, 399. 